\title{
Aberrant expression of let-7a miRNA in the blood of non-small cell lung cancer patients
}

\author{
HYE CHEOL JEONG ${ }^{1}$, EUN KYUNG KIM ${ }^{1}$, JI HYUN LEE ${ }^{1}$, \\ JI MIN LEE ${ }^{2}$, HAN NA YOO ${ }^{2}$ and JIN KYEOUNG KIM ${ }^{2}$ \\ ${ }^{1}$ Division of Respiratory and Critical Care Medicine, Department of Internal Medicine, CHA Bundang Medical Center, \\ CHA University, Gyeonggi-do 463-712; ${ }^{2}$ Department of Biomedical Science, College of Life Science, \\ CHA University, Gyeonggi-do 463-836, Republic of Korea
}

Received September 21, 2010; Accepted January 21, 2011

DOI: $10.3892 / \mathrm{mmr} .2011 .430$

\begin{abstract}
Abnormal expression of let-7a microRNA (miRNA) in non-small cell lung cancer (NSCLC) cells and tissue has been previously reported. Our objective was to investigate whether let-7a miRNA is aberrantly expressed in the blood of NSCLC patients. Using real-time PCR (RT-PCR), we analyzed let-7a miRNA in archived whole blood from 65 participants, 35 of whom had NSCLC and 30 of whom did not. Using RT-PCR, we also investigated the expression of let-7a miRNA in NSCLC cell lines (A549 and HCC 1588), a normal human lung fibroblast cell line (WI-38) and in 40 human NSCLC tissues. The $2^{- \text {ddCt }}$ of let-7a miRNA in the blood of normal subjects and those with NSCLC was $3242.49 \pm 355.28$ and $747.85 \pm 177.74$, respectively. The relative expression of let-7a miRNA in the A549 and HCC 1588 cancer cell lines was approximately 0.3 and 0.35 , respectively, compared to WI-38 cells. The $2^{- \text {ddCt }}$ of let-7a miRNA in the normal human lung tissues and human NSCLC tissues was 42.30 \pm 3.98 and $27.73 \pm 3.86$, respectively. Let-7a miRNAs were underexpressed in the blood of NSCLC patients, as well as NSCLC cells and NSCLC tissues, compared to normal controls. The possibility of using let-7a miRNA as a serologic marker for lung cancer warrants further study.
\end{abstract}

\section{Introduction}

MicroRNAs (miRNAs) are small (18-25 nucleotide in size) non-coding RNA molecules that function in the modulation of the activity of specific messenger RNA (mRNA) targets and play important roles throughout cellular development, proliferation and differentiation. The expression levels of miRNAs vary greatly among species and tissues. Over 700 miRNAs have been identified in human tissues. Some miRNAs are

Correspondence to: Dr Jin Kyeoung Kim, Department of Biomedical Science, College of Life Science, CHA University, 222 Yatap-dong, Bundang-gu, Seongnam-si, Gyeonggi-do 463-836, Republic of Korea E-mail: kyeoung66@hanmail.net

Key words: non-small cell lung cancer, blood, microRNA, let-7a linked to human malignancy and are differentially expressed in human cancer vs. matched normal tissue. There is increasing evidence to support the use of miRNA analysis for the diagnosis, prognosis and therapy of cancer (1-3). Some data from in vitro and in vivo studies have shown that miRNAs may have roles in the pathogenesis of lung cancer $(4,5)$. miRNA expression was shown to change linearly from normal bronchial tissue, hyperplasia, metaplasia, dysplasia and carcinoma (6). Crawford et al reported that miRNA-126 inhibits invasion in non-small cell lung carcinoma (NSCLC) cell lines (7). Fei et al reported that antibodies of miRNA-16, miRNA-21 and miRNA-214 inhibited human lung adenocarinoma (A549) cell growth by inducing apoptosis and S-phase arrest (8).

Recent publications have identified several miRNAs that were aberrantly expressed in primary lung cancer tissue (9). Depending on the genes that the miRNAs act on, they may serve to stimulate or suppress tumor formation and growth. Some of these miRNAs have been associated with the survival of NSCLC (10-12).

Let-7 miRNA, the second member of the miRNA family discovered in 2000, was initially found to control developmental timing in Caenorhabditis elegans. In humans, the let-7 family consists of 11 related genes and has been reported to be expressed at lower levels in lung cancer, both in vitro and in vivo. Reduced let-7 miRNA expression has been significantly associated with shortened postoperative survival $(13,14)$.

Recently, cancer-related miRNAs have also been identified in the serum of breast, pancreatic, colon and lymphoma patients (15-18). Microarray data showed the presence of some miRNAs in the serum of NSCLC patients (19). The objective of our study was to investigate the expression of let-7a miRNA in the blood of NSCLC patients compared to normal controls.

\section{Materials and methods}

Cell lines, tissues and blood. The established human A549 cell line, squamous cell carcinoma cell line (HCC 1588) and normal human lung fibroblast cell line (WI-38) were cultured under the appropriate conditions: A549 and HCC1588 cells were maintained with RPMI-1640 (Lonza) medium containing $10 \%$ fetal bovine serum (FBS; Lonza), streptomycin $(100 \mu \mathrm{g} /$ 
A

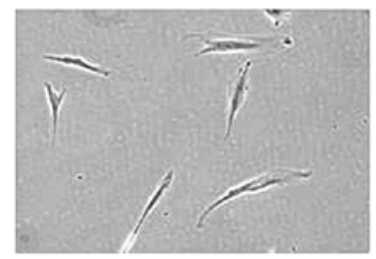

WI-38 (16 PDL)

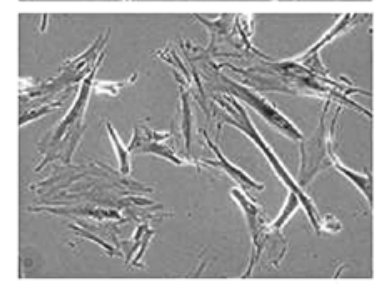

WI-38 (58 PDL)
B

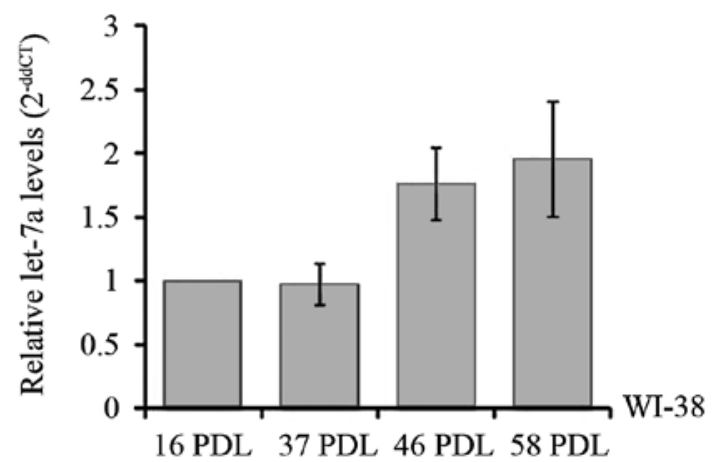

D

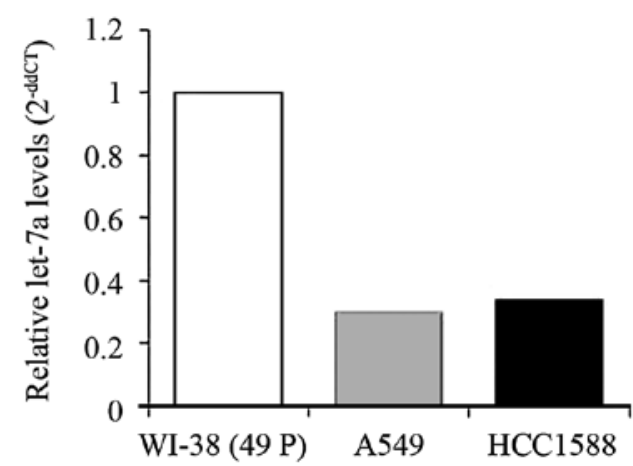

Figure 1. Expression of let-7a miRNA in normal lung fibroblast cells (WI-38) and non-small cell lung cancer cell lines (A549: adenocarcinoma, HCC1588: squamous cell carcinoma). (A) $\beta$-galactosidase staining at pH 6.0 on normal WI-38 cells at 16 PDL and senescent WI-cells at 58 PDL. (B) Expression of let-7a miRNA in WI-38 cells shows an increase according to (PDL. (C) Expression of let-7a miRNA in A549 cells was similar to that of WI-38 cells (16 PDL). The expression level of let-7a miRNA in HCC1588 cells was somewhat higher than that of WI-38 cells. (D) Expression of let-7a miRNAs in NSCLC (A549 and HCC1588) cells was lower than that of WI-38 cells (49 PDL). PDL is an intrinsic measure of the 'age' of the particular culture of a cell line.

$\mathrm{ml})$ and penicillin $\left(100 \mathrm{U} / \mathrm{mol}\right.$; Lonza) at $37^{\circ} \mathrm{C}$ in a humidified atmosphere containing $5 \% \mathrm{CO}_{2}$ in air. WI-38 cells were cultured in Eagle's minimal essential medium (EMEM; Lonza) with $10 \% \mathrm{FBS}$ at $37^{\circ} \mathrm{C}$ in $5 \% \mathrm{CO}_{2}$.

Forty surgically resected human lung cancer tissues and normal lung tissues were obtained from the National Korea Lung Tissue Bank. Tumor tissues were representative of the two histological types: 20 adenocarcinoma and 20 squamous cell carcinoma (patients did not receive previous treatment).

Venous blood $(35 \mathrm{ml})$ was collected from the antecubital fossa of 35 lung cancer patients prior to treatment, and from 30 normal subjects.

Permission regarding ethics and informed consent were obtained for the use of all samples.

RNA isolation and real-time quantitative PCR. Total RNA were isolated from lung cells and lung tissue by TRIzol (Molecular Research Center, Inc.) according to the manufacturer's instructions. Also, total RNA was isolated from blood by the easy-RED ${ }^{\mathrm{TM}}$ total RNA extraction kit (Intron biotechnology) as per the manufacturer's protocol. The concentration was quantified using a NanoDrop 1000 Spectrophotometer. Expression of let-7a miRNA was analyzed using quantitative real-time PCR (RT-PCR). Quantitative RT-PCR was performed with the TaqMan microRNA assay (Applied Biosystems Inc.). Normalization was performed with the small nuclear RNA U6 (RNU6B; Applied Biosystems Inc.). The nucleotide sequences of the primers were as follows: let-7a, 5'-UGAGGUAGUAGGUUGUAUAGUU-3'; RNU6B, 5'-CGC AAGGAUGACACGCAAAUUCGUGAAGCGUUCCAU AUUUUU-3'. All plates were performed in a Roter-gene 6 (Corbett Research).

$B$-galactosidase staining. The cells $\left(1 \times 10^{5}\right)$ were seeded in 6-well plates. After $24 \mathrm{~h}$, the cells were washed with $1 \mathrm{X}$ PBS, fixed for $10 \mathrm{~min}$ in $\beta$-galactosidase fixative ( $2 \%$ formaldehyde; $0.2 \%$ glutaraldehyde in PBS), washed again with $1 \mathrm{X}$ PBS, and finally stained for $24 \mathrm{~h}$ at $37^{\circ} \mathrm{C}$ in the absence of $\mathrm{CO}_{2}$ in staining solution $\left[150 \mathrm{mM} \mathrm{NaCl}, 2 \mathrm{mM} \mathrm{MgCl}_{2}, 5 \mathrm{mM}\right.$ $\mathrm{K}_{3} \mathrm{Fe}(\mathrm{CN})_{6}, 40 \mathrm{mM}$ citric acid and $12 \mathrm{mM}$ sodium phosphate, $\mathrm{pH}$ 6.0], containing $1 \mathrm{mg} / \mathrm{ml}$ 5-bromo-4-chloro-3-indolyl $\beta$-D-galactoside. Thereafter, cells were washed in $1 \mathrm{X}$ PBS, and the number of galactosidase activity-positive cells (blue staining) was counted under bright field illumination.

Statistical analysis. The $\mathrm{dC}_{\mathrm{t}}$ method was used for analysis $\left[\mathrm{dC}_{\mathrm{t}}=\right.$ mean Ct (RNU6B) - mean Ct (let-7a miRNA)] of the RT-PCR outcome. Statistical analysis was performed using SPSS 17.0 (PASW 17.0; Chicago, IL, USA). Statistical significance was evaluated using the Student's t-test for unpaired comparison; $\mathrm{P} \leq 0.05$ was considered statistically significant. The area under the receiver operation characteristic (ROC) curve was calculated to verify the accuracy of the expression of let-7a miRNA in the diagnosis of NSCLC. 


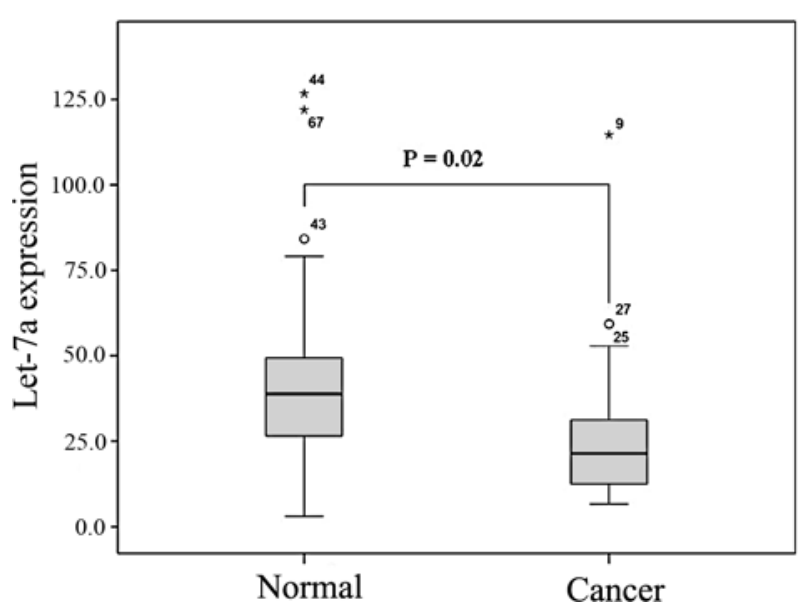

Figure 2. Expression of let-7a miRNA is lower in non-small cell lung cancer tissues than in normal lung tissues.

\section{Results}

Expression of let-7a miRNA in normal lung epithelial cell lines and NSCLC cells. Expression of let-7a miRNA in WI-38 cell lines showed an increasing trend according to the population doubling level (PDL). The PDL is an intrinsic measure of the age of the particular culture of a cell line (Fig. 1A). The expression level of let-7a miRNA in senescent WI-38 cells with 58 PDL was doubled compared to that of young WI-38 cells with 16 PDL (Fig. 1B). Therefore, let-7a miRNA may play a role in the senescence of lung fibroblast cells. To date, the expression of let-7a miRNA has been considered to be decreased in cancer cells. However, when we compared young WI-38 cells (16 PDL) to NSCLC cells, we could not find a difference in let-7a miRNA expression. Let-7a miRNA expression was somewhat higher in HCC1588 than in normal WI-38 cell lines (16 PDL) (Fig. 1C). However, the expression of let-7a miRNA was lower in lung cancer cell lines (A549 and HCC1588) than in normal WI-38 cells with 45 PDL, as expected. The relative expression of let-7a miRNA in the A549 and HCC1588 cancer cell lines was approximately 0.3 and 0.35, respectively, as compared to the WI-38 cells (Fig. 1D).

Expression of let-7a miRNA in normal lung tissues and NSCLC tissues. The median age of the NSCLC patients was 62 years. Twenty-nine patients were male and 11 were female. The number of patients with stage I was 10; with stage II, 7; with stage III, 20; and with stage IV, 3. A significant difference in the expression level of let-7a miRNA was observed between 40 normal lung tissues and 40 NSCLC tissues $(p=0.02)$. The expression of let-7a miRNA was down-regulated in NSCLC tissues compared to normal lung tissues (Fig. 2). The $2^{\text {-ddCt }}$ of let-7a miRNA in normal lung tissues and NSCLC tissues was $42.30 \pm 3.98$ and $27.73 \pm 3.86$, respectively. No difference in let-7a miRNA expression according to clinicopathologic features (age, gender, smoking status, histology and stage) was observed.

Expression of let-7a miRNA in the blood of normal subjects and NSCLC patients. There were no differences in baseline characteristics (gender, age and smoking status) between
Table I. Baseline characteristics of study populations.

\begin{tabular}{|c|c|c|}
\hline & \multicolumn{2}{|c|}{ No. $(\%)$} \\
\hline & $\begin{array}{l}\text { Lung cancer } \\
\qquad(\mathrm{n}=35)\end{array}$ & $\begin{array}{l}\text { Normal subjects } \\
\qquad(\mathrm{n}=30)\end{array}$ \\
\hline \multicolumn{3}{|l|}{ Gender } \\
\hline Male & $28(80)$ & $16(53)$ \\
\hline Female & $7(20)$ & $14(47)$ \\
\hline \multicolumn{3}{|l|}{ Age (years) } \\
\hline Median (range) & $67(48-84)$ & $60(37-80)$ \\
\hline \multicolumn{3}{|l|}{ Smoking } \\
\hline Current & $20(57)$ & $16(53)$ \\
\hline Ex-smoker & $9(25)$ & $10(33)$ \\
\hline Non-smoker & $6(17)$ & $4(13)$ \\
\hline \multicolumn{3}{|l|}{ Stage } \\
\hline I & $5(14)$ & \\
\hline II & 1 (3) & \\
\hline III & $16(46)$ & \\
\hline IV & $13(37)$ & \\
\hline \multicolumn{3}{|l|}{ Histological subtype } \\
\hline Adenocarcinoma & $18(51)$ & \\
\hline Squamous cell carcinoma & $15(43)$ & \\
\hline $\begin{array}{l}\text { Bronchioloalveolar cell } \\
\text { carcinoma }\end{array}$ & $1 \quad(3)$ & \\
\hline $\begin{array}{l}\text { Poorly differentiated } \\
\text { carcinoma }\end{array}$ & 1 (3) & \\
\hline
\end{tabular}

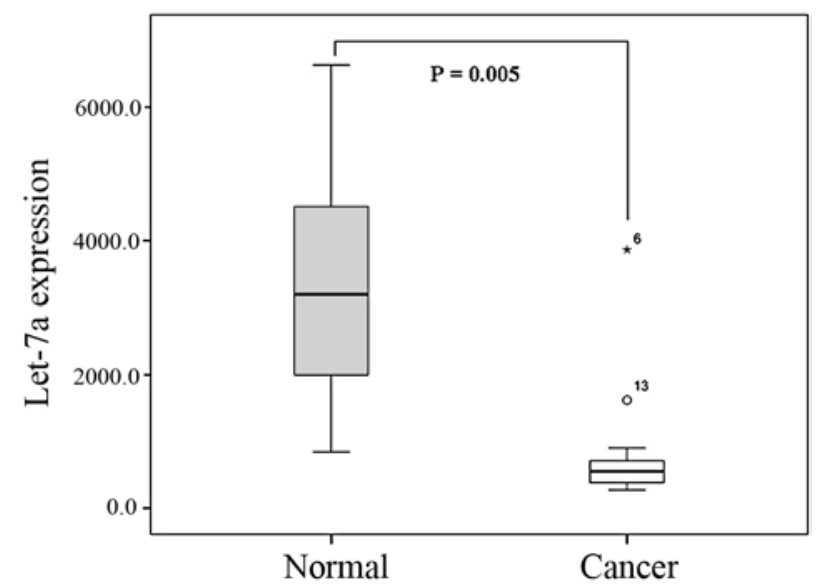

Figure 3. Blood level of let-7a miRNA is lower in non-small cell lung cancer patients $(n=35)$ than in healthy subjects $(n=30)(p=0.005)$.

normal subjects and NSCLC patients $(\mathrm{P}>0.05)$ (Table I). Most of the NSCLC patients had advanced stage disease. Among the 35 patients, 29 (83\%) were stage III and IV. The expression level of let-7a miRNA in whole blood samples from NSCLC patients $(n=35)$ was compared to those from healthy controls $(n=30)$. The $2^{-\mathrm{ddCt}}$ of let-7a miRNA in NSCLC was $747.85 \pm 177.74$ and $3242.49 \pm 355.28$ in normal subjects. The level of let-7a miRNA was down-regulated in the blood of NSCLC patients $(p=0005)$ (Fig. 3). The area under the ROC curve of let-7a miRNA expression in the whole blood was 0.951 . Sensitivity and specificity were 90.3 and $90.3 \%$, 


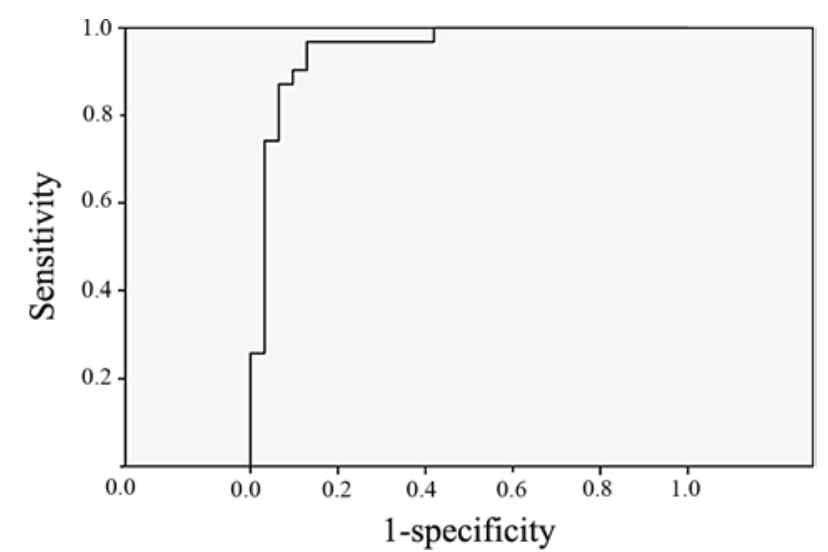

Figure 4. ROC curve of blood let-7a miRNA for the diagnosis of non-small cell lung cancer. The area under the ROC curve was $0.951(\mathrm{P}<0.0001)$.

respectively, at a cut-off value of 868.5 (Fig. 4). We investigated associations between let-7a miRNA and the clinicopathologic features of the NSCLC patients (age, gender, smoking history, histology and stage), but found no significant correlation.

\section{Discussion}

In the present study, we examined the expression of let-7a miRNA in the cells, tissues and blood of NSCLC. The degree of down-regulation was somewhat different in each sample. Among the miRNAs, blood let-7a miRNA was markedly decreased in the NSCLC samples.

There is a large amount of evidence indicating that the let-7 miRNA family is associated with the regulation of cell proliferation and differentiation during development. Let-7 miRNA has been reported to induce cell cycle arrest in the G1 phase by repressing the target genes involved in the traversion of the cell cycle (20). Let-7f miRNA and let-7g miRNA expression changed according to the stage of cell cycle arrest in WI-38 human fibroblasts (i.e., premature senescence, replicative senescence and quiescence) (21). Let-7 miRNA was undetectable in human and mouse embryonic stem cells; however, the level of let-7 increased upon differentiation (22). Let-7 miRNA has been associated with the neural differentiation of embryonal stem cells (23). Let-7 miRNA was also previously known as a regulator of the aging mechanism in Caenorhabditis elegans (24). In the results, we first described an increase in let-7a miRNA according to the age of the WI-38 cell line. The expression of let-7a miRNA in WI-38 cells with 58 PDL was over 2-fold more than that of WI-38 cells with 16 PDL (Fig. 1A). To the best of our knowledge, this phenomenon is an unknown finding. If we had not checked the PDL, we would not have been able to make a precise comparison of the expression of let-7a miRNA between WI-38 and NSCLC cells. These findings also suggest that let-7a miRNA may play a role in aging and senescence in the pathogenesis of fibrogenic lung reactions (25). The examination of the expression of let-7a miRNA in patients with fibrogenic lung disease, such as idiopathic pulmonary fibrosis or chronic obstructive pulmonary disease, is warranted.

The deregulation of let-7 miRNA has been shown to be a feature of many types of cancer, including lung cancer
(26). To date, the decreased expression of let-7 miRNA in NSCLC tissues has been reported in only a few studies. Most of these have investigated NSCLC tissues in the early stages. In this study, we investigated the expression of let-7a miRNA (among the let-7 family) in Korean NSCLC tissues that were in early and advanced stages. As expected, let-7a miRNA was down-regulated in all stages of NSCLC. The rate of decrease of let-7a was approximately $64 \%$ in 40 NSCLC tissues compared to 40 normal lung tissues. Notably, the rate of the decrease of let-7a miRNA was $23 \%$ in the blood of NSCLC patients compared to normal subjects. The sensitivity and specificity of blood let-7a miRNA in the diagnosis of NSCLC were high.

Aberrantly expressed miRNAs in the blood of lung cancer patients have been reported rarely. Microarray analysis of miRNAs in the serum of NSCLC patients only has recently been reported. The expression of some miRNAs differed between patients with longer and shorter survival. Serum miRNA-486, miRNA-30d, miRNA-1 and miRNA-499 were independent predictors of postoperative survival in NSCLC patients (27). Our report is the first to compare the downregulated expression of let-7a miRNA in the blood of NSCLC patients to that of normal subjects. To date, clinicians have not had an effective serologic marker for lung cancer. When lung cancer is suspected, they may check let-7a miRNA levels in the blood. If the $2^{-\mathrm{ddCt}}$ is lower than 800 , this indicates the need for invasive biopsy. These findings may be applied to the detection of early lung cancer. Variable clinical factors affect let-7 miRNA expression in the blood of normal subjects and lung cancer patients. Therefore, the findings of this study must be confirmed in a large scale sample.

The physiologic role of the depressed expression of let-7a in NSCLC patients remains uncertain. Many genes (i.e., RAS, Myc, Hmga2 and Cycin D1) may be targets of let-7a miRNA. The epidermal growth factor receptor (EGFR) gene has also been also regarded as candidate target gene. Zhong et al reported that let-7a miRNA inhibited the growth of NSCLC cells and enhanced the cytotoxicity of targeted agents (EGFR tyrosine kinase inhibitor) in vitro (28). Observation of the change of let-7a miRNA expression in the blood of NSCLC patients after EGFR tyrosine kinase inhibitor therapy would be informative.

There are some limitations to our study, including small sample size. Due to the short follow-up time, we could not prove the prognostic value of let-7a miRNA in the blood and tissue of NSCLC patients. Despite the above limitations, our study provided initial data on down-regulated blood let-7a miRNA in NSCLC patients, and suggested the diagnostic value of the analysis of blood let-7a miRNA in NSCLC patients. The development of minimally invasive tests for the detection and monitoring of cancer patients has long been a goal of cancer research. Circulating let-7a miRNA may have clinical utility for the diagnosis, monitoring and follow-up of patients with NSCLC. This should be explored by further studies conducted with larger sample numbers.

In conclusion, let-7a miRNA was down-regulated in the blood of NSCLC patients compared to normal subjects. This data suggests that blood let-7a miRNA has potential as a clinically useful non-invasive biomarker in lung cancer. 


\section{Acknowledgements}

This study was supported by grants from the Stem Cell Research Program (2006-2004127) of the Ministry of Education, Science, and Technology, and the National Research Foundation of Korea.

\section{References}

1. Iorio MV and Croce CM: MicroRNAs in cancer: small molecules with a huge impact. J Clin Oncol 27: 5848-5856, 2009.

2. Ortholan C, Puissegur MP, Llie M, Barbry P, Mari B and Hofman P: MicroRNAs and lung cancer: new oncogenes and tumor suppressors, new prognostic factors and potential therapeutic targets. Curr Med Chem 16: 1047-1061, 2009.

3. Lebanony D, Benjamin H, Gilad S, et al: Diagnostic assay based on has-miR-205 expression distinguishes squamous from nonsquamous non-small-cell lung carcinoma. J Clin Oncol 27: 2030-2037, 2009.

4. Wu X, Piper-Hunter MG, Crawford, Nuovo GJ, Marsh CB, Otterson GA and Nana-Sinkam SP: MicroRNAs in the pathogenesis of lung cancer. J Thorac Oncol 4: 1028-1034, 2009.

5. Nasser MW, Datta J, Nuovo G, Kutay H, Motiwala T, Majumder S, Wang B, Suster S, Jacob ST and Ghoshal K: Downregulation of micro-RNA-1 (miR-1) in lung cancer. Suppression of tumorigenic property of lung cancer cells and their sensitization to doxorubicin induced apoptosis by miR-1. J Biol Chem 283: 33394-33405, 2008

6. Mascaux C, Laes JF, Anthoine G, Haller A, Ninane V, Burny A and Sculier JP: Evolution of microRNA expression during human bronchial squamous carcinogenesis. Eur Respir J 33: 352-359, 2009

7. Crawford M, Brawner E, Batte K, Yu L, Hunter MG, Otterson GA, Nuovo G, Marsh CB and Nana-Sinkam SP: MicroRNA-126 inhibits invasion in non-small cell lung carcinoma cell lines. Biochem Biophys Res Commun 373: 607-612, 2008.

8. Fei J, Lan F, Guo M, Li Y and Liu Y: Inhibitory effects of antimiRNA oligonucleotides (AMOs) on A549 cell growth. J Drug Target 16: 688-693, 2008.

9. Liang Y: An expression meta-analysis of predicted microRNA targets identifies a diagnostic signature for lung cancer. BMC Med Genomics 1: 61-76, 2008.

10. Markou A, Tsaroucha EG, Kaklamanis L, Al-Majed AA, Al-Shabanah OA and Elkashef HA: Prognostic value of mature microRNA-21 and microRNA-205 over-expression in non-small cell lung cancer by quantitative real-time RT-PCR. Clin Chem 54: 1696-1704, 2008.

11. Hu Z, Chen J, Tian T, Zhou X, Gu H, Xu L, Zeng Y, Miao R, Jin G, Ma H, Chen Y and Shen H: Genetic variants of miRNA sequences and non-small cell lung cancer survival. J Clin Invest 118: 2600-2608, 2008

12. Yu SL, Chen HY, Chang GC, et al: MicroRNA signature predicts survival and relapse in lung cancer. Cancer Cell 13: 48-57, 2008.

13. Takamizawa J, Konishi H, Yanagisawa K, Tomida S, Osada H, Endoh H, Harano T, Yatabe Y, Nagino M, Nimura Y, Mitsudomi T and Takahashi T: Reduced expression of the let-7 microRNAs in human lung cancers in association with shortened postoperative survival. Cancer Res 64: 3753-3756, 2004.
14. Yanaihara N, Caplen N, Bowman E, Seike M, Kumamoto K, Yi M, Stephens RM, Okamoto A, Yokota J, Tanaka T, Calin GA, Liu CG, Croce CM and Harris CC: Unique microRNA molecular profiles in lung cancer diagnosis and prognosis. Cancer Cell 9: 189-198, 2006.

15. Mitchell PS, Parkin RK, Kroh EM, et al: Circulating microRNAs as stable blood-based markers for cancer detection. Proc Natl Acad Sci USA 105: 10513-10518, 2008.

16. Lawrie CH, Gal S, Dunlop HM, Pushkaran B, Liggins AP, Pulford K, Banham AH, Pezzella F, Boultwood J, Wainscoat JS, Hatton CS and Harris AL: Detection of elevated levels of tumorassociated microRNAs in serum of patients with diffuse large B-cell lymphoma. Br J Haematol 141: 672-675, 2008.

17. Ho AS, Huang X, Cao H, Christman-Skieller C, Bennewith K, Le QT and Koong AC: Circulating miR-210 as a novel hypoxia marker in pancreatic cancer. Transl Oncol 3: 109-113, 2010.

18. Lodes MJ, Caraballo M, Suciu D, Munro S, Kumar A and Anderson B: Detection of cancer with serum miRNAs on an oligonucleotide microarray. PLos One 4: e6229, 2009.

19. Hu Z, Chen X, Zhao Y, Tian T, Jin G, Shu Y, Chen Y, Xu L, Zen K, Zhang C and Shen H: Serum microRNA signatures identified in a genome-wide serum microRNA expression profiling predict survival of non-small cell lung cancer. J Clin Oncol 28: 1721-1726, 2010.

20. Johnson CD, Esquela-Kerscher A, Stefani G, Byrom M, Kelnar K, Ovcharenko D, Wilson M, Wang X, Shelton J, Shingara J, Chin L, Brown D and Slack FJ: The let-7 microRNA represses cell proliferation pathways in human cells. Cancer Res 67: 7713-7722, 2007.

21. Maes OC, Sarojini H and Wang E: Stepwise up-regulation of microRNA expression levels from replicating to reversible and irreversible growth arrest states in WI-38 human fibroblasts. J Cell Physiol 221: 109-119, 2009.

22. Thomson JM, Parker J, Perou CM and Hammond SM: A custom microarray platform for analysis of microRNA gene expression. Nat Methods 1: 47-53, 2004.

23. Thomson JM, Newman M, Parker JS, Morin-Kensicki EM, Wright $\mathrm{T}$ and Hammond SM: Extensive post-transcriptional regulation of microRNAs and its implications for cancer. Genes Drv 20: 2202-2207, 2006.

24. Ibanez-Ventoso C, Yang M, Guo S, Robins H, Padgett RW and Driscoll M: Modulated microRNA expression during adult lifespan in Caenorhabditis elegans. Aging Cell 5: 235-246, 2006.

25. Araya $J$ and Nishimura SL: Fibrogenic reactions in lung disease. Annu Rev Pathol 5: 77-98, 2010.

26. Boyerinas B, Park S, Hau A, Murmann AE and Peter ME: The role of let-7 in cell differentiation and cancer. Endocr Relat Cancer 17: F19-F36, 2010.

27. Hu Z, Chen X, Zhao Y, Tian T, Jin G, Shu Y, Chen Y, Xu L, Zen K, Zhang C and Shen H: Serum microRNA signatures identified in a genome-wide serum microRNA expression profiling predict survival of non-small cell lung cancer. J Clin Oncol 28: 1721-1726, 2010

28. Zhong M, Ma X, Sun C and Chen L: MicroRNAs reduce tumor growth and contribute to enhance cytotoxicity induced by gefitinib in non-small cell lung cancer. Chem Biol Interact 184: 431-438, 2010. 